\title{
Gestão escolar, situações de conflito e violência: campo de tensão em escolas públicas
}

\section{Public schools management and situations of conflict and violence: field of tension in public schools}

\author{
Angela Maria Martins ${ }^{1}$ \\ Cristiane Machado ${ }^{2}$
}

\begin{abstract}
RESUMO
Este artigo tem o objetivo de apreender o que pensam diretores escolares sobre situações de conflito e violência, por meio de um estudo qualitativo realizado com 43 diretores de escolas da rede estadual de ensino de São Paulo, unidades que estão inseridas no Sistema de Proteção Escolar, programa implementado pela Secretaria de Estado da Educação de São Paulo desde 2010. Compõe pesquisa mais ampla que busca analisar a relevância que o tema das situações de conflito vem logrando no campo das políticas públicas de educação. Como conclusão, o estudo aponta para a existência de número significativo de respostas cautelosas e contraditórias, o que pode indicar que os diretores não se sentem preparados para enfrentar os desafios postos pelas situações de conflito; para a não oferta de formação continuada condizente com a necessidade de construção do conhecimento sobre a legislação que envolve adolescentes e jovens em situações de conflito; para a ausência significativa de respostas dos diretores nas questões referentes às ações que foram adotadas em situações de conflito e violência, porém, quando estas são citadas se referem a chamar a família, os responsáveis ou os próprios
\end{abstract}

\section{DOI: $10.1590 / 0104-4060.44074$}

1 Universidade Cidade de São Paulo. Mestrado Profissional Formação de Gestores Educacionais. Fundação Carlos Chagas. São Paulo, São Paulo, Brasil. Rua Quitanduba, nº 363. CEP: 05516-030.E-mail: ange.martins@uol.com.br

2 Universidade Cidade de São Paulo. Programa de Pós-Graduação em Educação. Mestrado em Educação e Mestrado Profissional Formação de Gestores Educacionais. São Paulo, São Paulo, Brasil. Rua Cesário Galeno, nº 448/475. CEP: 03071-000. E-mail: cristiane13machado@ yahoo.com.br 
alunos; a acionar órgãos colegiados escolares; à realização de palestras e projetos alternativos; a mobilizar a equipe de gestão e os Professores Mediadores Comunitários. Os recursos externos como órgãos de segurança e rede de apoio são acionados quando os recursos anteriores foram esgotados.

Palavras-chave: conflitos em escolas; políticas educacionais; gestão escolar.

\begin{abstract}
This article aims to seize what school principals think about conflict and violence situations by taking a qualitative study performed with 43 principals of state schools in São Paulo, which are units inserted in the School Protection System, that is a program implemented by the State Education Secretariat of São Paulo since 2010. It composes broader research that seeks to analyze the fact that the theme of conflict situations has been achieving relevance in the field of public policies on education. In conclusion, the study points to the existence of a significant number of cautious and contradictory answers, which may indicate that the principals do not feel prepared to face the challenges posed by situations of conflict; lack of continuing education to build the necessary knowledge on legislation involving adolescents and young people in conflict situations; significant lack of response from the principals in matters relating to actions that were adopted in situations of conflict and violence - but when these are mentioned they refer to call the family, responsible or the students themselves; triggering school collegiate bodies; holding lectures and alternative projects; mobilizing the management team and the Teachers who are Community Mediators. External support such as security organs and support network are triggered when the previous remedies have been exhausted.
\end{abstract}

Keywords: conflicts in schools; educational policies; school management.

\title{
Introdução
}

No cenário contemporâneo brasileiro, identifica-se a centralidade que o tema dos conflitos e da violência escolar logrou, particularmente, no estado de São Paulo, impulsionando a criação do programa de governo denominado Sistema de Proteção Escolar (SPE), por meio da Resolução SE nº 19, de 12 de fevereiro de 2010. Entre 1996 e 2010, os projetos da Secretaria de Estado da Educação de São Paulo (SEESP), voltados para enfrentar situações de conflito, podem ser divididos em dois grupos: no primeiro, os que incentivavam a 
participação da comunidade na escola e desenvolviam atividades de atenção à saúde, destacando-se o Projeto "Comunidade Presente", o Projeto "Prevenção Também se Ensina" e o Programa "Escola da Família". No segundo grupo, estão os projetos que apontavam a necessidade de se incentivar o sentimento de pertencimento da comunidade escolar, indicando um movimento para a realização de ações de prevenção ao uso de drogas, de bebidas alcoólicas e da depredação do ambiente: o Projeto "Prevenção ao Consumo de Álcool nas Escolas Estaduais" e o Projeto "Justiça Restaurativa em Heliópolis e Guarulhos: Parceria para a cidadania", envolvendo escolas da região de Guarulhos (Região Metropolitana da Grande São Paulo), e de Heliópolis, na periferia da capital paulista, forneceram elementos para a futura elaboração do Sistema de Proteção Escolar. (GOMES; MARTINS, 2014).

Desenvolvido por meio de parcerias entre a Justiça, a Educação, a Comunidade e o Conselho Tutelar, este último projeto apresentava como eixo central a aprendizagem de procedimentos restaurativos pelos facilitadores voluntários, que iriam operar nos Círculos Restaurativos nas escolas, no Fórum e na comunidade. Para isso, a SEESP organizou o Curso de Formação de Lideranças Educacionais, do qual participavam cinco integrantes de cada unidade escolar juntamente com os gestores do Sistema Judiciário (Juiz e Promotor). Entretanto, o documento oficial da SEESP aponta que ocorreram resistências no interior das escolas por parte de diretores, coordenadores, professores e funcionários, pois estes assinalavam que a indisciplina não mais seria contida, tendo em vista que apenas o diálogo não resolveria as questões conflituosas, além de provocar a perda de sua autoridade. (SÃO PAULO, 2007). Ressalte-se que não é tarefa simples romper com medidas disciplinares consagradas culturalmente nas redes de escolas - e, muitas vezes, legitimadas na família -, dinâmica que pode acabar apoiando formas de castigo para crianças e jovens, pois muitos dos profissionais da educação podem acreditar que este tipo de disciplina ainda é a mais adequada para a aprendizagem e para a manutenção de um ambiente disciplinado e disciplinador.

O estudo aqui analisado ${ }^{3}$ tem o objetivo de apreender o que pensam diretores escolares sobre situações de conflito e violência nas escolas, tomando por base estudo qualitativo realizado com 43 diretores de escolas de unidades da rede estadual de ensino que estão inseridas no Sistema de Proteção Escolar em

3 Este estudo é desdobramento de investigação mais ampla intitulada "Conflitos no espaço escolar: a gestão de escolas públicas em contextos vulneráveis", cujo propósito é analisar o Sistema de Proteção Escolar que apresenta como objetivo central instaurar na rede pública de escolas do estado de São Paulo ações para prevenir, mediar e resolver conflitos, com financiamento do Conselho Nacional de Desenvolvimento Científico e Tecnológico (CNPq) e da Fundação Carlos Chagas. 
Guarulhos, São Paulo 4 . Parte do pressuposto que no cotidiano escolar instituem-se processos de (re)interpretação do conjunto normativo e legal, preconizado por órgãos centrais, e tem como propósito desvelar que (re)interpretações são essas. Pondera, também, que conflitos emergem cotidianamente nos contextos escolares e, ao não serem razoavelmente elaborados, podem se configurar como problemas graves de indisciplina ou se transformar em situações de violência física. A questão central que se procurou responder foi: de que forma esses diretores expressam conhecimento do escopo legal do programa e como atribuem relevância a aspectos/fatos/situações/acontecimentos envolvendo conflitos nas escolas por eles administradas?

Salienta-se a relevância de estudos que analisam programas de governo e lançam mão de documentos e fontes oficiais para examinar os fundamentos políticos e pedagógicos do conjunto normativo-legal e das diretrizes das reformas educacionais, o que permite compreender condicionantes que impactam na formulação e na implementação das políticas e contribuir para a construção de um campo crítico de teorias e debates. Destaque-se, além disso, que a realização de estudos etnográficos e os usos de procedimentos de campo originados na antropologia e/ou na sociologia, tais como a realização de observações, entrevistas de aprofundamento, dinâmicas de grupo, grupos focais - aliados à análise de documentos oficiais e medidas legais -, como é o caso da investigação apresentada, constituem uma possibilidade mais flexível de realização de pesquisas na área. (SULBRANDT, 1994; RUS PEREZ, 1999).

\section{Conflitos e violências: do que estamos falando?}

A palavra conflictus significa "com" (junto) e fligere significa "bater", o que indica violência. Entretanto, são atos distintos, embora uma situação de conflito mal resolvida possa redundar em agressões físicas, muitas vezes, graves. Estudos realizados em torno do tema apresentam diferentes delineamentos, com predominância de textos argumentativos em detrimento de pesquisas de campo. Contudo, é possível identificar convergência de ideias no que se refere à ausência de preparação adequada de professores e gestores para en-

4 A rede estadual de ensino de Guarulhos, segundo dados do Instituto Brasileiro de Geografia e Estatística (IBGE, 2015), possui 111.940 matrículas no Ensino Fundamental e 5.415 funções docentes para a mesma etapa. Abarca 175 escolas e, destas, 43 solicitaram o Sistema de Proteção Escolar, foco do estudo aqui analisado. 
frentar situações de conflito que podem redundar em violência verbal e física. (CECCON et al., 2009).

Abramovay e Rua (2002) assinalam que na literatura contemporânea os especialistas têm privilegiado a análise da violência entre alunos ou a violência desses para com a escola e, em menores proporções, a violência que ocorre entre alunos e professores. Também identificaram que é frequente o esforço dos pesquisadores em tentar encontrar uma definição, o mais abrangente possível, para os diferentes tipos de violência que ocorrem nas escolas. No entanto, as especificidades dos trabalhos realizados com abordagens diferenciadas acabam enfatizando alguns aspectos em detrimento de outros, exigindo que cada um construa a sua definição sobre violência mais adequada.

Ressalte-se que nos anos de 1980, o foco dos estudos estava na discussão de segurança nas escolas, envolvendo o patrimônio; nos anos de 1990, a análise apresentava como eixo as interações entre alunos ou destes com os adultos, culminando na elaboração do Estatuto da Criança e do Adolescente (ECA). Gradativamente, o campo da análise se ampliou para a compreensão da dinâmica escolar, tomando por base interações entre professores, alunos, direção e pais. A partir da aprovação do ECA, as situações de conflito e violência envolvendo adolescentes e crianças passaram a ser amplamente divulgadas pela mídia. (LOPES, 2004).

Além disso, as sociedades modernas padecem de uma constante sensação de insegurança por motivos diversos. As movimentações econômicas, como instabilidade na economia, no emprego, no custo de vida; os avanços tecnológicos que aceleram as informações de todos os tipos e gêneros; a agressividade cada vez maior dos acidentes ambientais e climáticos; os riscos à saúde pública com novas epidemias fragilizam continuamente as organizações sociais. Acrescente-se a esse contexto, conforme explicita Martuccelli (1999), o fato de que os meios de comunicação estão mais eficientes na exposição das mazelas sociais, levando as pessoas a perceberem a violência em maior grau do que efetivamente ocorre.

Nos espaços escolares, a ocorrência de situações de conflito e violência pode ser vista a partir de múltiplos fatores, especialmente quando parte-se do reconhecimento das especificidades/singularidades de cada escola, como é o caso deste estudo. Assim, implica levar em consideração os contextos sociais nos quais estão localizadas; a dinâmica de organização e funcionamento pedagógico e administrativo; as demandas configuradas pelo escopo normativo de órgãos centrais e os fatores econômico-sociais e culturais.

Nessa perspectiva, a discussão centrada nas relações de ensino e de aprendizagem - com foco nos aspectos que dificultam a permanência de alunos no fluxo dos sistemas e redes - vem cedendo espaço para a necessidade de compreensão das relações mais amplas entre alunos e suas famílias, diretores, professores e 
funcionários. Dessa forma, as unidades de ensino precisariam se preparar para enfrentar contextos adversos, pois são inúmeras as dificuldades para implementar posturas mais adequadas no enfrentamento de conflitos, geralmente oriundos de situações não resolvidas ou, no limite, mal resolvidas, provocando (re)ações que podem chegar a agressões físicas. (GOMES; MARTINS, 2014; ABRAMOVAY; RUA, 2002; CECCON et al., 2009; CHARLOT, 2002; CARDIA, 1999). Este contexto delineado impele os governos a adotarem ações que possam enfrentar ou pelo menos concorrer com o desafio posto pelas relações cada vez mais conflituosas e intolerantes.

\section{O Sistema de Proteção Escolar: diretrizes legais}

Após os projetos desenvolvidos entre 1996 a 2010, citados anteriormente, a Secretaria de Estado da Educação de São Paulo criou o Programa Sistema de Proteção Escolar (SPE), implantado por meio da Resolução SE n 19, de 12 de fevereiro de 2010, apontando a necessidade de se instaurar na rede pública de escolas do estado de São Paulo ações para prevenir, mediar e resolver conflitos. As escolas que optam por se inscrever no referido sistema devem atender a uma série de critérios: baixo Índice de Desenvolvimento da Educação do Estado de São Paulo (IDESP); razoável número de registros de ocorrências de conflitos; localização em região considerada vulnerável pela Secretaria de Estado da Educação de São Paulo. Para operacionalizar o referido Programa, as escolas - levando em conta fatores de vulnerabilidade e de risco a que estão expostas - podem contar com até 2 (dois) docentes, para o desempenho das atribuições de Professor Mediador Comunitário Escolar (PMEC), selecionados pelas Diretorias de Ensino, seguindo algumas prioridades: em primeiro lugar, titular de cargo docente da própria unidade escolar que se encontrasse na condição de adido (sem aula atribuída, cumprindo horário de permanência); em segundo, docente readaptado e, por último, docente ocupante da função atividade. Com a instituição dessa resolução, ficou também regulamentado o Sistema Eletrônico de Registro de Ocorrências Escolares (ROE), constituindo-se em instrumento de informações on-line para o registro, por parte do Diretor da Unidade Escolar, das ações ou situações de conflito ou indisciplina, danos patrimoniais, furtos, ou ações que possam caracterizar atos infracionais.

Diretrizes legais e orientações normativas significativas foram preconizadas para regulamentar o SPE. Entretanto, tendo em vista que o foco deste artigo não está voltado para a análise desse escopo, serão destacadas apenas 
as principais medidas, a saber: a Resolução $\mathrm{SE}^{\mathrm{0}}$ 1, de 20 de janeiro de 2011; a Resolução $S E n^{\circ} 7$, de 19 de janeiro de 2012a; a Resolução $S E n^{\circ} 18$, de 28 de março de 2012b; o Manual de Normas Gerais de Conduta Escolar (SÃO PAULO, 2009a); Manual de Proteção Escolar e Promoção da Cidadania (SÃO PAULO, 2009b). Registre-se que a adesão cada vez maior de escolas da rede estadual de São Paulo ao Sistema de Proteção Escolar chama a atenção pela rápida ampliação do referido Programa. Atualmente, a rede estadual de ensino de São Paulo possui quase três mil Professores Mediadores Comunitários, um aumento de quase $50 \%$ desde seu início ${ }^{5}$, em 2011 , o que mostra a centralidade que as questões de conflito e violência vêm logrando na implementação de políticas educacionais.

\section{O percurso metodológico}

Trata-se, aqui, de estudo exploratório (STAKE, 2011), tendo em vista que o tema analisado - como diretores expressam conhecimento do escopo legal do SPE e atribuem relevância a aspectos, fatos e situações envolvendo conflitos nas escolas por eles administradas - não tem sido objeto de pesquisa e das produções científicas na área da educação. Ressalte-se que a coleta de dados em uma pesquisa exploratória pode ser realizada por meio de diversos procedimentos: entrevistas; questionários semiestruturados; observações de campo; grupo focal; dinâmicas de grupo; levantamento de medidas legais e documentos oficiais. Assim, na pesquisa original procuramos cumprir as etapas previstas para o desenvolvimento de investigações exploratórias, a saber: levantamento de informações baseadas em documentos oficiais e na legislação, com vistas a ampliar e aprofundar o conhecimento sobre a temática; leitura e sistematização de literatura pertinente ao tema; aproximações sucessivas ao campo por meio de reuniões técnicas com equipes de supervisores e diretores escolares de Diretorias de Ensino Regionais do estado de São Paulo, com o propósito de coletar informações/opiniões iniciais acerca do objeto. (STAKE, 2011). Esses procedimentos possibilitaram a apropriação de informações relevantes, contribuindo para a ampliação da visão sobre o fenômeno em estudo e a estruturação do instrumento de campo.

É importante salientar que, neste artigo, recortamos o trabalho desenvolvido apenas junto à Diretoria de Ensino (DER) de Guarulhos/Sul, onde aplica-

5 Disponível em: $<$ http://www.educacao.sp.gov.br/spec/seminario-protecao-escolar-debate-temas-bullying-prevencao-conflitos/>. Acesso em: 20 jul. 2015. 
mos um questionário semiestruturado a 43 diretores de escolas públicas, todas inseridas no Sistema de Proteção Escolar, organizado em quatro blocos: a) o primeiro, dividido em duas seções, sendo que a primeira solicitava o registro das situações de conflito e violência nas unidades escolares com a frequência (nunca; às vezes; frequentemente), a segunda seção solicitava a livre descrição das ações adotadas para enfrentar situações de conflito e violência (os respondentes poderiam assinalar várias ações); b) o segundo bloco, constituído por questões abertas que buscavam registrar suas percepções a respeito das funções e atribuições do Professor Mediador Comunitário (PMEC), tendo em vista que esse profissional é o responsável por articular mediações em situações de conflito; este bloco ainda instava os diretores a se manifestarem livremente a respeito da instauração (ou não) de práticas pedagógicas renovadas para seu enfrentamento, após a adesão ao Sistema de Proteção Escolar, por meio do exercício das funções do PMEC; c) o terceiro bloco versava sobre o perfil profissional do diretor; d) o quarto bloco foi composto por itens de livre associação.

Neste artigo apresentam-se dados e análises dos três primeiros blocos do instrumento semiestruturado, a saber: registro das situações de conflito e violência nas unidades escolares e descrição das ações adotadas para enfrentar situações de conflito e violência (primeiro bloco); registro das percepções a respeito das funções e atribuições do Professor Mediador Comunitário (PMEC) (segundo bloco) e perfil profissional do diretor (terceiro bloco). As respostas obtidas por itens de livre associação (quarto bloco), para este artigo, não serão objeto de exame. As informações do primeiro e do segundo blocos do instrumento foram compiladas por recorrência de conteúdos e agrupadas por similitude em classes de análise. Em outros termos, os dados foram organizados conforme a análise de conteúdo proposta por Bardin (1994), que faculta a percepção e o entendimento das mensagens quando separadas pela frequência de ideias contidas nas respostas dos questionários. Para a autora, a técnica da análise de conteúdos constitui-se em um composto de técnicas de análise das comunicações em que são utilizados procedimentos para a descrição do conteúdo de mensagens.

$\mathrm{Na}$ fase inicial de análise buscou-se a organização dos dados obtidos de forma a identificar e agrupar por descrição os conteúdos que, de acordo com a autora "[...] são operações de classificação de elementos constitutivos de um conjunto, por diferenciação e por reagrupamento segundo critérios previamente definidos". (BARDIN, 1994, p. 117). Na sequência, as categorias analíticas emergiram da leitura preliminar (descrição) do material coletado, após sua organização a partir das respostas dadas e reagrupadas de acordo com sua frequência. Assim, foram construídas as seguintes categorias: 1) violência contra o patrimônio: depredação/pichação em áreas internas e externas da escola; roubo e furto de equipamentos e materiais; 2) situações de tráfico, porte e uso 
de drogas; 3) uso de álcool nas dependências da escola e em seu entorno; 4) violência interpessoal: agressões verbais e físicas entre alunos; 5) violência interpessoal: agressões verbais e físicas de funcionários a alunos; 6) formas de registros efetuados sobre situações de violência e conflito no espaço escolar.

\section{$O$ enfrentamento de situações de conflito e violência em escolas públicas: campo de tensão da gestão escolar}

Inicialmente, apresenta-se o perfil dos diretores participantes do estudo. Do total de participantes, 26 respondentes são mulheres $(60,4 \%)$ e 16 homens $(37,2 \%)^{6}$, distribuídos nos seguintes cargos: 19 diretores efetivos $(44,1 \%) ; 2$ diretores designados $(4,6 \%) ; 12$ vice-diretores $(27,9 \%) ; 7$ professores $(16,2 \%)$ em substituição a diretores; 3 coordenadores pedagógicos representando diretores ausentes $(11,6 \%)$. A maior parte dos respondentes apresenta formação superior inicial em pedagogia (32,5\%), seguida por diversas licenciaturas: $6,2 \%$ com formação em matemática; $13,9 \%$ com formação em história; $11,6 \%$ com formação em letras; 4,6\% com formações em biologia e geografia e 2,3\% em química. Identifica-se também formação em magistério $(6,9 \%)$ e outros cursos específicos (4,6\% em gestão escolar e psicologia). O corpo diretivo das escolas apresenta também uma característica de estabilidade, com $60,4 \%$ ocupando a direção das escolas na rede estadual há mais de 4 anos; $27,8 \%$ de 4 a 9 anos de exercício; $16,2 \%$ de 10 a 15 anos; $9,3 \%$ de 16 a 20 anos; e $6,9 \%$ com mais de 21 anos neste cargo; do restante, $16,2 \%$ o exercem de 1 a 3 anos na rede e outros $16,2 \%$ o exercem há menos de 1 ano. Em se tratando de sua permanência nas escolas, $37,2 \%$ dos diretores afirmam estar trabalhando na atual escola entre 4 a 9 anos, seguida de $32,5 \%$ deles apresentando de 1 a 3 anos de trabalho na escola atual; $13,9 \%$ com menos de 1 ano de trabalho.

Do total de respondentes, $72 \%$ afirmam não acumularem cargo na rede estadual; do percentual restante, $16,2 \%$ acumulam cargo como professor na esfera municipal; $4,6 \%$ na rede privada; $2,3 \%$ na esfera estadual e $2,3 \%$ acumulam cargos na esfera federal. Em suma, os diretores apresentam um perfil estável e em torno de $44 \%$ deles exerce a função entre 4 a 15 anos, sendo que a maioria não acumula cargos, o que permite inferir que esses profissionais têm experiência razoável no cargo e tempo de dedicação no exercício da função. Na sequência, busca-se identificar e compreender o que pensam a respeito das

6 Um(a) diretor(a) não identificou seu gênero. 
situações de conflito e violência, por meio das questões que registravam sua frequência nas unidades escolares, assim como a livre descrição das ações adotadas para enfrentá-las. Da mesma forma, procura-se registrar suas percepções no que se refere às funções e atribuições do Professor Mediador Comunitário, por meio da livre manifestação a respeito da instauração (ou não) de práticas pedagógicas renovadas para seu enfrentamento, após a adesão ao Sistema de Proteção Escolar.

\section{Primeira categoria de análise - violência contra o patrimônio: depredação/pichação em áreas internas e externas da escola; roubo e furto de equipamentos e materiais}

No que diz respeito à depredação/pichação nas dependências externas e internas das escolas, $70 \%$ dos entrevistados afirmam que isso ocorre às vezes, $\mathrm{e}$ $18 \%$ frequentemente; $12 \%$ afirmam que essa situação nunca ocorre. Quanto às soluções adotadas por eles, $30 \%$ afirmam adotar resoluções internas ${ }^{7}$ (levam a situação para a Associação de Pais e Mestres - APM e outros órgãos colegiados, e/ou para a equipe de gestão, talvez em movimento de retirar a decisão solitária do diretor); $28 \%$ chamam os pais/responsáveis ou até os próprios alunos, no caso de adolescentes; $21 \%$ chamam a Polícia Militar (PM) ou a Guarda Civil Metropolitana (GCM); apenas 9\% acionam a rede de apoio: Conselho Tutelar e/ou órgão competente (sem especificação). No que tange a roubo/furto de equipamentos ou a profissionais e alunos, em torno de $61 \%$ afirmam que isso ocorre às vezes e $16 \%$, frequentemente; $23 \%$ dos diretores afirmam que isso nunca ocorre em suas escolas. Quanto às ações adotadas para enfrentar essas situações, 49\% acionam PM ou GCM; em segundo lugar - 28\% - adotam as denominadas resoluções internas; em terceiro lugar - 19\% - afirmam chamar os pais, responsáveis ou os alunos, no caso de adolescentes. Chama atenção o fato de que $30 \%$ dos diretores não responderam a esta questão.

7 Optamos por denominar resoluções internas porque as respostas são amplas: os diretores levam os casos para os órgãos colegiados (APM; conselhos escolares); registram no Registro Eletrônico de Ocorrência (ROE) e/ou afirmam registrar em livros de atas; realizam palestras; elaboram projetos/ações; acionam o PMEC; monitoram a entrada e a saída de alunos. 


\section{Segunda categoria de análise - situações de tráfico, porte e uso de drogas}

No que se refere ao consumo, porte, tráfico nas dependências ou proximidade da escola, 53\% afirmam ter vivenciado este tipo de situação às vezes, e 47\% frequentemente. Chama atenção o fato dos diretores não assinalarem "nunca" $\mathrm{e}$ nem terem deixado de responder a esta questão, o que pode indicar que a situação de envolvimento de adolescentes e jovens com as drogas tem se ampliado. Para enfrentar essa situação, em primeiro lugar $-72 \%$ dos diretores - chamam a PM ou a GCM; em segundo lugar - 28\% - afirmam chamar os pais, responsáveis e/ ou os alunos, no caso de adolescentes; $16 \%$ adotam as denominadas resoluções internas e 16\% acionam a rede de apoio, neste caso, a Unidade Básica de Saúde (UBS). Registre-se que 7\% dos diretores não responderam quais ações adotam nesses casos, embora todos tenham respondido vivenciar algum tipo de situação envolvendo alunos com porte, uso e tráfico de drogas.

\section{Terceira categoria de análise - uso de álcool nas dependências da escola e em seu entorno}

Para $70 \%$ dos diretores, há casos de consumo de álcool nas dependências e/ou proximidades da escola, às vezes e, para 14\%, frequentemente; apenas $16 \%$ afirmam nunca terem vivenciado essa situação. Para enfrentá-la, a ação mais adotada tem sido a de chamar os pais, responsáveis e/ou alunos $-35 \%$ -, sendo ainda que 30\% deles chamam a PM ou GCM. Em torno de $19 \%$ dos diretores afirmam encaminhar o problema para as chamadas resoluções internas. Destaque-se que 25,5\% dos diretores não registraram quais ações adotam para encaminhar/resolver o problema.

Quarta categoria de análise - violência interpessoal: agressões verbais e físicas entre alunos

Há um predomínio de agressões verbais entre alunos: $35 \%$ afirmam que isso ocorre às vezes, porém, $65 \%$ dizem que essa situação ocorre frequentemen- 
te; há uma inversão quando se trata de agressão física, pois $81 \%$ dos diretores afirmam ocorrer às vezes e apenas $14 \%$ afirmam que isso ocorre frequentemente. Infere-se que discussões entre alunos provocadas por inúmeros fatores (disputas variadas entre grupos/gangues; problemas familiares que repercutem na escola) podem configurar o centro dos problemas a serem enfrentados. Sem uma adequada organização da escola para encaminhar soluções e renovar suas práticas pedagógicas, essa dinâmica pode se transformar em caldo explosivo, com potencial para redundar em agressões físicas intrapessoais generalizadas.

Verificam-se, também, discrepâncias que merecem registro no que tange às soluções/encaminhamentos adotados para enfrentar essas situações. Quando se trata de agressão verbal, $65 \%$ dos diretores chamam os pais, responsáveis e/ou os próprios alunos; em segundo lugar o Professor Mediador Comunitário é acionado; em torno de 52\% adotam as chamadas resoluções internas e $11 \%$ acionam a rede de apoio; apenas 2\% chamam a PM ou GCM. Quando se trata de agressão física, os órgãos de segurança são acionados em primeiro lugar (45\%); em segundo lugar (40\%), os pais são chamados. No que diz respeito a agressões verbais e físicas de alunos aos profissionais da escola, há diferenças significativas entre a primeira e a segunda situação: $75 \%$ afirmam que vivenciam agressões verbais às vezes; $13 \%$ frequentemente e $12 \%$ nunca vivenciaram esse tipo de situação. Quando se trata de agressões físicas, $75 \%$ afirmam que isso nunca ocorre; $19 \%$ às vezes e apenas $6 \%$ registram que ocorre com frequência. Como se disse anteriormente, a predominância de agressões verbais em relação às agressões físicas - em outros termos, as discussões e provocações de alunos a profissionais da escola - podem ser provocadas por inúmeros fatores: resistência a determinadas aulas; aluno ocioso, sem aula e sem projetos para se envolver; disputas variadas entre grupos/gangues, com desdobramentos para todo o espaço escolar; problemas familiares que repercutem na escola, transpostos para a necessidade de enfrentar a figura de autoridade representada pelos profissionais da escola, entre muitos outros que poderiam ser citados. Infere-se que, neste caso, o papel da mídia é relevante quando divulgam fatos de agressões físicas ocorridas no espaço escolar, sem contextualizar o fenômeno, resumindo-se a expor a situação de vitimização, o que, sem dúvida, comove os leitores/espectadores.

Chamar os pais, responsáveis e/ou os próprios alunos para resolver as agressões verbais é apontada como a ação mais adotada por $49 \%$ dos diretores; nesta situação, o PMEC também é bastante chamado para resolver o conflito, pois esta opção é assinalada por $25,5 \%$ dos diretores; em torno de $42 \%$ apontam que adotam resoluções internas, com predominância, neste caso, de encaminhamento para a equipe de gestão, novamente na tentativa, muito provavelmente, de retirar dos ombros do diretor as decisões a serem tomadas. Chama a atenção que nos casos de agressões físicas entre os alunos, mais da metade dos diretores 
não registrou quais ações adotam, o que permite assinalar algumas inferências, tais como: insegurança; indecisão sobre as ações mais coerentes ou adequadas a serem adotadas; ausência de interesse em expor ideias próprias, entre outras.

\section{Quinta categoria de análise - violência interpessoal: agressões verbais e físicas de funcionários a alunos}

Para mais da metade dos diretores - 59\% - às vezes ocorrem casos de agressão verbal de profissionais da escola contra alunos; outros $41 \%$ registram que nunca ocorre este tipo de situação. Quanto à agressão física, os 43 diretores afirmam que isso nunca acontece. Nenhum diretor deixou de registrar a resposta, neste caso. Acionar as resoluções internas é a ação mais adotada para $47 \%$ diretores; chamar os pais, responsáveis e/ou alunos aparece em segundo lugar, com $19 \%$ de recorrências, e $12 \%$ acionam o PMEC.

\section{Sexta categoria de análise - percepção dos diretores a respeito das funções e atribuições do Professor Mediador Comunitário}

Do total de entrevistados, 43 diretores, $79 \%$ afirmam ter boa relação com os Professores Mediadores Escolares e Comunitários. Sobre o papel do PMEC na escola, $81 \%$ dos diretores assinalam a mediação de conflitos, por meio da orientação, diálogo e intervenção como papel deste professor. Em seguida, 21\% destes apontam a prevenção de conflitos; $14 \%$ o desenvolvimento de projetos; $11 \%$ o aconselhamento da equipe gestora e dos docentes; $9 \%$ o acompanhamento e encaminhamento de alunos; e 7\% a integração da equipe escolar. Do restante, $2 \%$ ainda apontam o auxílio no processo de ensino e aprendizagem e outros $2 \%$ o estabelecimento de regras de convivência. Quando perguntados em relação às mudanças percebidas na escola com a criação dessa função, $47 \%$ dos diretores afirmam ter presenciado a diminuição dos casos de conflito interpessoal entre a comunidade escolar; $23 \%$ percebem melhoria no atendimento aos alunos; e 16\% apontam que houve uma mudança de cultura ou melhora no ambiente escolar, porém sem especificar qual tipo de melhora ou mudanças ocorreram. Dos demais respondentes, $5 \%$ apontam diminuição dos casos de violência patrimonial; 5\% 
afirmam ter ocorrido melhoria na assiduidade dos alunos; e outros $5 \%$ indicam que a relação com as famílias foi facilitada.

Para $51 \%$ dos respondentes, um pouco mais da metade dos diretores entrevistados, o estabelecimento de diálogo com os pais ou responsáveis é a principal ação que o PMEC desenvolve na escola; seguida pelo desenvolvimento de projetos $-37 \%$; atendimento e orientação aos alunos - 35\%; e mediação de conflitos $-33 \%$. Ainda, $12 \%$ dos diretores apontam como principal ação deste professor o estabelecimento de diálogo com os órgãos externos (Conselho Tutelar, Vara da Infância, entre outros); e 9\% apontam a orientação da equipe escolar. Questionados sobre os limites e as dificuldades na realização do trabalho do professor mediador, $40 \%$ dos diretores afirmam a pouca presença e participação dos pais convocados para conversas na escola como um dos principais empecilhos e $30 \%$ assinalam que o excesso de demanda para o tempo de trabalho é o que mais prejudica e dificulta as ações deste profissional.

\section{Considerações}

Destaque-se, inicialmente, a ausência significativa de respostas em todas as questões que se referem às ações que os diretores adotaram em situações de conflito e violência, sobretudo, no que se refere à agressão física de alunos aos profissionais da escola; em segundo lugar, quais ações seriam adotadas nas ocorrências de agressões verbais de profissionais a alunos; em terceiro lugar, sobre roubo/furto em suas escolas. Da mesma forma, boa parte dos respondentes não assinalou quais ações adotam quando há consumo de álcool nas dependências das escolas ou em sua proximidade, assim como o que fazem em situações de depredação/pichação nas dependências internas e externas das escolas.

As possíveis contradições identificadas em situações envolvendo roubo de equipamentos, porte e uso de drogas, violência física, talvez possam ser creditadas à ausência de visão e discernimento para resolvê-las de forma mais adequada. Ao invés de acionarem, prioritariamente, os mecanismos internos das escolas - os órgãos colegiados (APM; conselhos escolares); realização de palestras; elaboração de projetos/ações específicos para esse fim; acionar o PMEC -, optam por chamar a Polícia Militar e/ou a Guarda Civil Metropolitana. Ao contrário, observa-se que nos casos mais "leves" - agressões verbais, depredação/pichação - outras ações são adotadas, antes de envolver órgãos de segurança e a rede de apoio: os diretores afirmam chamar a família, os responsáveis ou os próprios alunos; acionam os órgãos colegiados escolares; realizam 
palestras e projetos alternativos; mobilizam a equipe de gestão e os Professores Mediadores Comunitários. Identifica-se a importância das funções atribuídas pelos diretores ao PMEC.

Depositar no "outro" as responsabilidades por problemas que deveriam ser assumidos no exercício das próprias funções profissionais não é exatamente uma novidade no campo da educação. A transferência sempre é um caminho confortável em situações desafiadoras, da mesma forma como respostas e/ou (re)ações enquadradas normativamente, pois a legislação pode ser uma zona de conforto, para o bem e para o mal. Identificou-se que boa parte das respostas eram cautelosas e contraditórias, e isto pode ser computado a inúmeros fatores: os programas educacionais são modificados constantemente e isto requer dos diretores mobilidade para resolver problemas imediatos e atender as diretrizes legais; não se sentem preparados para enfrentar os desafios postos em situações de conflito; ausência de estabilidade profissional no quadro dos Professores Mediadores Comunitários, pois eles não são efetivos e podem mudar de escola todos os anos; a não oferta de formação continuada adequada para a construção do conhecimento necessário sobre a legislação envolvendo adolescentes e jovens em situações de conflito, ampliando a visão dos diretores para discernir entre fenômenos de indisciplina - comuns aos jovens dessa faixa etária - e situações de violência física.

Nesse sentido, maiores envolvimentos em ações implementadas por órgãos centrais podem ser vistos com algum distanciamento por esses profissionais redundando em respostas que reproduzem as diretrizes legais - o que configura um espaço de conforto "burocrático" no exercício da direção escolar. Ademais, não se pode desprezar o papel da mídia na divulgação dos fatos envolvendo adolescentes, jovens, professores, diretores e funcionários em situações de conflito e violência em escolas públicas, o que potencializa o sentimento coletivo de insegurança, medo e impotência para articular ações coerentes no enfrentamento dessas situações, construindo um campo de tensão nas práticas de diretores escolares. Saliente-se que escolas situadas em regiões vulneráveis tendem a ter mais dificuldades de efetivarem estratégias para encontrar soluções aos inúmeros problemas que enfrentam. Como se disse anteriormente, situações de indisciplina - comuns no comportamento de adolescentes e jovens - poderiam ser mais equacionadas se as políticas públicas de educação promovessem a continuidade das ações voltadas para uma prevenção contínua e não apenas adotassem ações momentâneas pontuais. O Projeto Político Pedagógico, por exemplo, poderia suscitar nos profissionais da escola a mudança de atitudes e de valores por meio de atividades de formação continuada que incluíssem a discussão e a análise de situações conflituosas, incluindo-se no processo a discussão sobre o rol de atribuições do Professor Mediador Comunitário. Em suma, no entrecruzamento 
de diferentes culturas que se configuram no espaço escolar é necessário instaurar novas formas de acolhimento das diferentes visões de mundo que (con)vivem nas escolas públicas, sobretudo, no que tange a situações de conflito envolvendo crianças, adolescentes e jovens.

\section{REFERÊNCIAS}

ABRAMOWAY, M.; RUA, M. G. (Coords.). Violência nas escolas. Brasília: Unesco, 2002.

BARDIN, L. Análise de conteúdo. Portugal: Edições 70, 1994.

CARDIA, N. Pesquisa sobre atitudes, normas culturais e valores em relação à violência em 10 capitais brasileiras. Brasília: Ministério da Justiça, Secretaria de Estado dos Direitos Humanos, 1999.

CECCON, C. et al. Conflitos na escola: modos de transformação: dicas para refletir e exemplos de como lidar. São Paulo: CECIP: Imprensa Oficial do Estado de São Paulo, 2009.

CHARLOT, B. A violência na escola: como sociólogos franceses abordam essa questão. Sociologias, Porto Alegre, Ano 4, n. 8, p. 432-443, jul./dez. 2002.

GOMES, R. A.; MARTINS, A. M. A normatização do sistema de proteção escolar em São Paulo: situações de conflitos no espaço escolar. Revista@mbienteeducação, Universidade Cidade de São Paulo, v. 7, n. 2, p. 230-242, maio/ago. 2014. Disponível em: $<$ http://arquivos.cruzeirodosuleducacional.edu.br/principal/old/revista_educacao/pdf/volume_7_2/Educa\%C3\%A7\%C3\%A3o_01-2014_230-242.pdf>. Acesso em: 14 abr. 2015.

IBGE - Instituto Brasileiro de Geografia e Estatística. Cidades@. 2015. Disponível em: $<$ http://cidades.ibge.gov.br/xtras/perfil.php?lang=\&codmun=351880\&search=s ao-paulo|guarulhos>. Acesso em: 05 mar. 2015.

LOPES, R. B. Significações de violências na perspectiva de professores que trabalham em escolas "violentas". Dissertação (Mestrado em Educação) - Universidade Católica de Brasília, Brasília, 2004.

MARTUCCELLI, D. Reflexões sobre a violência na condição moderna. Tempo Social. Revista de Sociologia, USP, n. 1, p. 157-175, maio 1999.

RUS PEREZ, J. R. Avaliação do processo de implementação: algumas questões metodológicas. In: RICO, E. M. Avaliação de políticas sociais: uma questão em debate. São Paulo: Cortez, 1999. p. 65-74. 
SÃO PAULO (Estado). Secretaria de Estado da Educação. Justiça e Educação em Heliópolis e Guarulhos: parceria para a cidadania. São Paulo: CECIP, 2007.

SÃO PAULO (Estado). Secretaria de Estado da Educação. Manual de Proteção Escolar e Promoção da Cidadania. Sistema de Proteção Escolar. São Paulo: FDE, 2009a.

SÃO PAULO (Estado). Secretaria de Estado da Educação. Normas Gerais de Conduta Escolar. Sistema de Proteção Escolar. São Paulo: FDE, 2009b.

SÃO PAULO (Estado). Secretaria de Estado da Educação. Resolução $S E n^{\circ} 19$, de 12/02/2010. Institui o Sistema de Proteção Escolar na rede estadual de ensino de São Paulo e dá providências correlatas. São Paulo: CENP/DRHU, 2010.

SÃO PAULO (Estado). Secretaria de Estado da Educação. Resolução $S E n^{\circ} 1$, de 20/01/2011. Dispõe sobre o exercício das atribuições de Professor Mediador Escolar e Comunitário do Sistema de Proteção Escolar e dá providências correlatas. São Paulo: CENP/DRHU, 2011.

SÃO PAULO (Estado). Secretaria de Estado da Educação. Resolução SE $n^{\circ}$ 07, de 19/01/2012. Dispõe sobre o exercício das atribuições do Professor Mediador Escolar e Comunitário do Sistema de Proteção Escolar, e dá outras providências. São Paulo: CENP/DRHU, 2012a.

SÃO PAULO (Estado). Secretaria de Estado da Educação. Resolução $S E n^{\circ} 18$, de 28/03/2012. Altera a Resolução SE n ${ }^{\circ} 1$, de 20 de janeiro de 2011, que dispõe sobre o exercício das atribuições de Professor Mediador Escolar e Comunitário do Sistema de Proteção Escolar e dá outras providências. São Paulo: CENP/DRHU, 2012b.

SÃO PAULO (Estado). Secretaria de Estado da Educação. Seminário de Proteção Escolar - debate temas como bullying e prevenção de conflitos. Disponível em: $<\mathrm{http}: / / \mathrm{www}$. educacao.sp.gov.br/spec/seminario-protecao-escolar-debate-temas-bullying-prevencao-conflitos/>. Acesso em: 20 jul. 2015.

SULBRANDT, J. A avaliação dos programas sociais: uma perspectiva crítica dos modelos usuais. In: KLISBERG, B. (Org.). Pobreza: uma questão inadiável. Brasília: ENAP, 1994. p. 365-409.

STAKE, R. Pesquisa qualitativa - estudando como as coisas funcionam. Porto Alegre: Penso, 2011.

Texto recebido em 25 de novembro de 2015. Texto aprovado em 28 de janeiro de 2016. 
